\title{
On the Ambiguity Caused by the Language Structure in the Legal Case
}

\author{
Yanran Shang, Shui Jin* \\ ${ }^{1}$ China Publishing House Beijing, China \\ ${ }^{2}$ School of Advertisement, Beijing Institute of Fashion Technology, China \\ * Corresponding author
}

Keywords: Legal writing; ambiguity; grammar; structure

\begin{abstract}
In today's society where the legal system is increasingly perfect, the law is closely related to everyone's life. The law intertwines with language, and is inseparable from it as the law is expressed through language which is the carrier of the law. As an interdisciplinary subject, legal writing has its own characteristics. As a special phenomenon of language, ambiguity is more or less reflected in legal writing, affecting people's legal life and thus becoming an important subject of legal writing research. Based on the typical legal cases in our daily life, the paper studied the influence of ambiguity caused by the Chinese grammatical structure on the formation, judgment and interpretation of legal disputes, and made a brief analysis of that issue.
\end{abstract}

\section{Introduction}

In recent years, with the continuous deepening of the rule of law in China, the legal system of our country has been improving, and the concept of the legal system has been deeply rooted in people's minds. The idea of rights protection has been strengthened. The law is no longer a simple superstructure, but gradually penetrates into people's daily lives, as the "legal report" and "law popularization" programs keeps cropping up on TV, news reports, and mobile digital media, making people's concerns about some typical legal disputes rise to a new height. In many case disputes, whether the legal language is proper or not often becomes an important factor in determining whether an arbitration award or a legal judgment is clear in power and responsibility, and it affects the universality, authority and impartiality of the law. Therefore, in the field of law and linguistics, the study of legal linguistics has gradually attracted more and more attention.

Ambiguity is a relatively special relationship between the structures and meanings of language, that is, the language of the same structure has two or more meanings. Due to the complexity and limitations of the language itself, the ambiguity is inevitable in our daily communication. This has also become a cause of legal disputes and has received widespread attention. In modern social legal disputes, the linguistic ambiguity is nothing new. Some people capitalize on this characteristic for certain purposes. And some cases are caused by unstrict contract formulation which resulting in various explanations. There are also the contexts where words cannot express the true intentions of the parties. Moreover, the limitations of the language itself also bring ambiguity. These fully demonstrate that the linguistic ambiguity is widely spread in the application of law, causing inconvenience to the parties and judges in the process of applying the law. In order to solve this kind of problem, the Supreme People's Court and the Supreme People's Procuratorate generally use judicial interpretation. However, using one language to interpret another language also has the probability of repetition and ambiguity. The law and language have a relationship of opposition and unity.

\section{Ambiguity Caused by Improper Abbreviations}

\section{Case 1}

At about 8 pm on a certain day, Mr. Jiang and his friends came to a restaurant on Yan'an 3rd Road to eat. In the restaurant, there is a prominent sign that says "For every Zhongcan consumption reaches RMB 100, receive RMB 30." When checking out, Mr. Jiang calculated according to the preferential policy 
and deemed that the 400 yuan actual meal fee should be discounted into 280 . However, the restaurant staff denied and replied that the "Zhongcan" referred to lunch, not dinner, so he should pay 400 yuan without discount. Mr. Jiang held that "Zhongcan" should be literally understood as "Chinese meal" or "Chinese style meal", opposite to Western food. As neither could convince the other, Mr. Jiang turned to the State Administration for industry and commerce. Law enforcement officials believed that for the understanding of the term "Zhongcan", "Chinese meal" or "Chinese style meal" is more appropriate, and the sign language should be immediately removed as it is ambiguous and misleading. As the result, the restaurant returned RMB 120 to Mr. Jiang.

This is a dispute caused by language ambiguity. Different people may hold different ideas about some incidents due to their knowledge or perspective differences, which will cause variance in word meaning. And when using some words, the people may not understand the exact meaning and connotation of them. If this variance is compensated by the specific context, it will not affect normal communication. Otherwise, it will lead to the ambiguity that the language form cannot accurately convey the its content. Xiong Xueliang called the meaning of a word more easily understood by people as "psychological positioning" ${ }^{1}$. Obviously, in the above case, the context in which the restaurant posted the announcement cannot eliminate the two-fold understanding that the term "Zhongcan" brings to people.

"Zhongcan" in Chinese is an ambiguous abbreviation which can refer to lunch and also Chinese food. When shortening long words, we must consider the four basic principles: "simplification principle", "sequence principle", "semantic relevance principle" and "differentiation principle". Among them, the simplification principle requires forming the abbreviations with the least morphemes from the original words. The "sequence principle" means that the first morpheme is usually selected in the same part to form an abbreviation. The first word of "noon" and "Chinese" is "Zhong" in Chinese. So is it appropriate to abbreviate "lunch" and "Chinese food" as "Zhongcan"? According to the semantic relevance principle, the morphemes that contain the prominent meanings and the semantics of the original words are selected as the elements of the abbreviations. "Zhongwu" ("noon” in English) is a joint word with "Zhong” and "Wu" both meaning the middle of the day. And both words can represent "noon". What's more, the word "zhong” has more common meanings - "China”, "Chinese style”, "Chinese”, etc. Therefore, when seeing the word "Chinese", it is hardly for people to think of "noon". Whereas, the meaning of "Wu" is relatively simple, and people will directly associate it with noon. Let's look at some examples of acronyms below:

Zhongwu fan-Zhongwu+fan- Wufan(lunch)

Zhongwu jiao-Zhongwu+jiao- Wujiao(siesta)

Zhongwen Zimu-Zhongwen+Zimu-Zhongzi

Zhongshi Canguan- Zhongshi+Canguan-Zhongcanguan

Zhongguo Dianying Jituan Gongsi(China Film Group

Corporation)-Zhongguo+Dianying+Jituan+Gongsi-Zhongying Jituan

It can be seen that the meaning of "Zhong" has a bigger degree of relation with "China". And it would be better to abbreviate "noon" to "Wu" in Chinese. From this case, we can clearly see the misunderstanding in people's lives caused by improper abbreviation. From the perspective of the court, interpreting according to the meaning of the text and the public order to avoid the misunderstanding is the basic requirement of a case. This speculation of the store undermines the basic rules of the language, which cannot be backed up by the law.

\section{The Ambiguity Due to Inappropriate Sentence Punctuation}

\section{Case 2}

On Dec. 6th, 2005, Wang Rongjiang placed orders with Li Chaofeng with 28 file cabinets, which would be paid on delivery. Then Wang only took 27 iron file cabinets and one cabinet for information. Li delivered the file cabinets to designated locations. Wang received the goods and wrote Li a receipt 
saying, "27 iron cabinets have been received from the supplier today, the amount of uncollected information cabinet is outstanding." One week later, Li delivered the information cabinet to appointed place. Then Li asked for the payment for many times, but Wang refused. Wang believed that, according to the punctuation on receipt, it meant 27 iron cabinets have been received from the supplier today; only the amount of uncollected information cabinet is outstanding. However, Li thought that all payment is not made. The two ways of punctuation had totally different means.

On Mar. 27th, 2007, Taixing People's Court issued its judgment. Following the court verdict, defendant Wang Rongjiang shall pay 12960 yuan to the plaintiff Li Chaofeng in 10 days after the entry into force of the judgment.

Due to the complexity of verbal communicative activity, speakers, in order to achieve special social aims, often use many methods on purpose, which would make listeners have different understanding and lead to ambiguity. After close scrutiny, it is easy to see that buyer Wang Rongjiang intentionally misses out a comma, so as to default. In this case, Wang was both the consignee and payer, Li asked him to write a certification for receipt, instead of payment. Therefore, the first half of the sentence, " 27 iron cabinets have been received from the supplier today", is the real aim for this certification. The second part after a comma is the supplement, in line with our daily communication and expression. The sentence "the amount of uncollected information cabinet is outstanding" emphasizes on "one cabinet has not been received". It means that the core content of this receipt is "we have received xx cabinets, having xx short", while "the amount is outstanding" supplied the former receipt. Namely, this is a consignment sheet instead of an IOU. The language is concise and straight. The point lies in " 27 iron cabinets have been received from the supplier today, having one information cabinet short", whereas "the amount is outstanding" supplied the later items. And it may reveal that "we shall pay after receiving all goods". If we understand it in " 27 iron cabinets have been received from the supplier today, the amount of uncollected information cabinet is outstanding." Thus, this ambiguous sentence only mentions how many goods had received, leaving out whether the payment had done. However, the second half of the sentence said that buyer had not paid the uncollected cabinet. The two parts is incoherent, disagreeing with our custom of communication and cognition. Therefore, this explanation seemed a little far-fetched. Wang exploited this ambiguity, attempting to default the payment.

\section{The Ambiguity Caused by Different Levels}

\section{Case 3}

In December, 1993, Zang in his seventies fell down from his bike, and had been admitted to a hospital in Jiangsu. After leaving the hospital, his injury took a long time to heal, but the bones went on to malunion and left lower limb functional limitations. Later, Zang was diagnosed with third level disability. Disputes between him and doctors arouse. Zang's son, as his deputy, signed a compensation agreement with the hospital, which says that the hospital paid off 10,000 yuan for compensation (payment after signing), then noted that "I disagree (with,) the notarization in the event of everything, I am responsible". The hospital paid 10,000 yuan along with the agreement, which was received by Zang's son. In January, 2006, Zang died. His family thought that the treatment of hospital caused huge economic and mental damage to the patient, so their agreement with the hospital was invalid. Then they appealed to the People's Court in Suining, Jiangsu, claim damages for various items from the hospital for over 600 thousand Yuan.

Through this case, we can see another discrepancy in linguistics, namely discrepancy of levels. That is because the different ways to make a pause in sentences, which causes two patterns-simple sentences and compound sentences. Thus, the meaning is quite different. This case ended up in court conciliation that the family members of the patient reached an agreement with the hospital. Firstly, if we add a comma to the sentence, the ambiguity will eliminate. 
(1) I disagree, after the notarization, in event of everything, I am responsible. (This is the opinion of the patient who refuses to take in charge, even notarization is conducted. That is to say the hospital should be partly responsible.)

(2) I disagree with the notarization, in event of everything, I am responsible. (This is the view of the hospital who believes that the patient fails to conduct notarization and takes the outcomes willingly. Thus, the hospital is irresponsible for the compensation.)

In spite of a comma, it would have different meaning in different position. Sentence (1) is simple, so we could analyze it with analytical hierarchy process. The result is as follows.

I disagree (with,) the notarization in the event of everything, I am responsible.

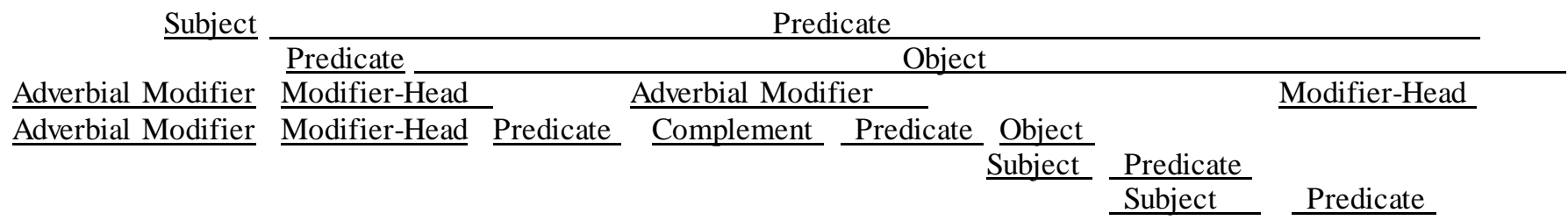

Sentence (2) is compound: "I disagree with the notarization, in event of everything, I am responsible." The two parts have a progressive relationship, namely, this is a compound sentence with progressive relationship. According to the original sentence, the one without comma is more similar to simple sentence. However, if patient's family mean the later one that "notarization" has nothing to do with "after", the comma is essential.

\section{The Ambiguity Caused by Homograph}

\section{Case 4}

In Match, 2007, Song lent Huang 300 thousand yuan and Huang wrote an IOU. In October, 2007, Huang paid back some of the debt and noted on the IOU that "paid back (remaining) 250 thousand yuan". However, Huang died in a car incident. Then, Song asked Huang's heir for 250 thousand yuan. But Huang's heir thought, the note on the IOU meant Huang had already paid back 250 thousand yuan. Thus, he or she only agreed repaying the remaining 50 thousand. However, Song claimed that the note meant that Huang had fallen behind on the payments for 250 thousand yuan. Therefore, Song appealed to the court, asking Huang's heir to pay back the debt of 250 thousand yuan.

\section{Case 5}

Zhang and Gao were neighbors and colleagues. Two years ago, Zhang borrowed 14,000 yuan from Gao. This year, in July, Zhang paid back part of the debt to Gao and wrote a debit note, which said, "Zhang borrowed RMB14,000 yuan from Gao, now Zhang paid back (still owed) 4,000 yuan." However, Zhang never returned the money. Gao appealed to the court, claiming that Zhang still owed him 10,000 yuan. But Zhang argued that he only owed 4,000 to the plaintiff.

The Chinese characters' coinage of Feng, Ya, Song, Fu, Bi and Xing (genres and methods to write poem) makes one character show different meanings. Some meanings even lead to words with different pronunciations, which is typical in Chinese. In daily communication, we could distinguish the meaning of phrases by pronunciation. In terms of paperwork, however, especially legal documents, we often forget to note words with pronunciation. That causes the ambiguity. The above cases focus on the character "还 (return or still)”. In the Contemporary Chinese Dictionary, “还” has two term to explain its meaning. One reads as "hái", meaning "increasing in some degree or supplying beyond some range", while another reads as "huán”, meaning "returning”. In addition, “debt” has different meanings. Therefore, when the two characters are used together, the ambiguity is easily occurred. Having a look at “还” + “欠款” : 


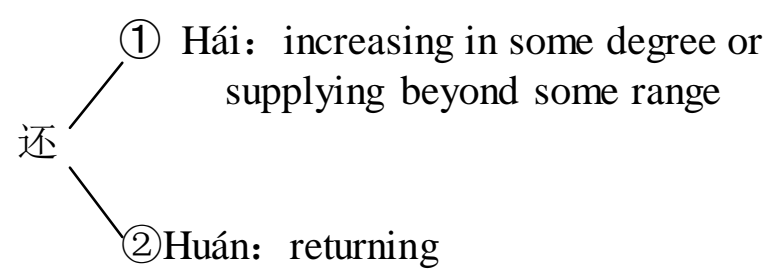

(2)Huán: returning

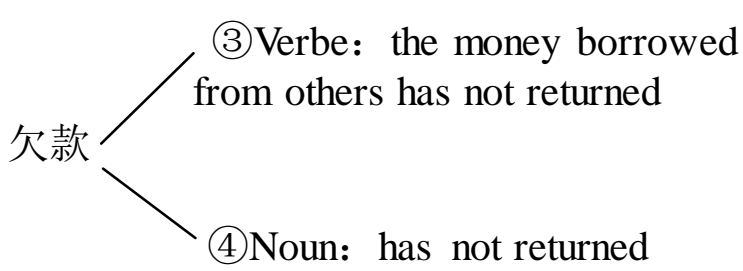

(1) + (3): still owing sb. XX yuan

(2) + (4): returning sb. XX yuan

This shows that the two phrases in four items could lead to two different meanings. "still owing sb. XX yuan" means the debtor still have to XX yuan to return, whereas "returning sb. XX yuan" means the debtor has returned $\mathrm{XX}$ yuan to the creditor and only need to pay back the remaining part.

Here are the judgements of the court:

In case 4, the court sentenced that Huang's heir shall pay 250 thousand yuan back to Song. (It is believed that “还” should read as “hái”, namely Huang’s heir hall pay 250 thousand yuan to Song.)

In case 5, the court sentenced that Zhang shall return Gao 100 thousand yuan. (It is believed that “还” should read as "huán", namely Zhang has already returned 4,000 thousand yuan, still having to return 10,000 yuan.)

With regard of law, in the setting and performance of the contract, both parties should comply with the principle of good faith and desirability, while the former is the "imperial principle" in Contract Law and Civil Law. According to the Contract Law, while setting the contract, if the words from one party could rationally draw two conclusions, the explanation going against the provider shall be accepted. The legal basis is to protect the relatively weak one. In above three cases, the debit notes were written by the debtor. Therefore, in the final judgement, the debtors should return more. All three cases comply with the principle.

According to the literal meaning, we analyze the sentence "paid back (still owed) " in different context, it is easy to explain the actual meaning of “还(return or still)". They both write IOU for supplement. The general pattern of the IOU is as follows.

$$
\begin{aligned}
& \text { Year, Month, Day, Huang borrowed Song RMB } 300 \text { thousand Yuan. } \\
& \text { Year, Month, Day, Huang still owes Song RMB } 250 \text { thousand Yuan. }
\end{aligned}
$$

In case 5 , the debit note is written by the debtor while returning the money without adding words or sentences. Its general model is as follows.

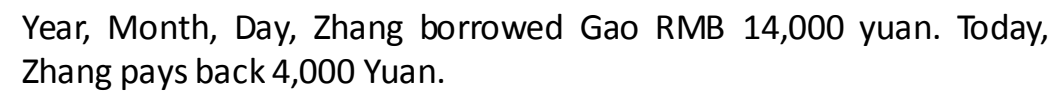

Through the two debit notes, it could be figured out that the first note owns by debtor, which means that the creditor changes the original note. This shows that they first illustrate one fact and then complement it. Therefore, it is believed that "Year, Month, Day, Huang borrowed Song RMB 300 thousand yuan; Year, Month, Day, Huang still owes Song RMB 250 thousand yuan.” The two numbers are amount in arrears, instead of payment amount, which complies with our intellectual coherence. If the client means "returning the amount in arrears", he or she should mark the name of person returning the money in the second time. It is likely that "Year, Month, Day, Huang borrowed Song RMB 300 thousand yuan; Year, Month, Day, Huang returned (huán) Song RMB 250 thousand yuan.” In terms of the second debit note, it is a certification of the creditor. From his or her aspect, the aim of this note is to claim the 
borrowed and returned amount, instead of borrowed and unpaid amount. Furthermore, behind the adverbials of time “today”, we should add a verbal "return(还huán), instead of adverbs "still(hái)".

The most outstanding feature of legal language is precise, which is vital. It could not only makes legal language strict and precise, but also avoid the misjudgment because of the inaccurate expression. From these cases, in order to do a great legal work, we must first understand the language and strengthen the research of ambiguity. Thus, it could better serve the law and obey the justice, making the judgement more precise and rational.

\section{References}

[1]. Xiong Xueliang. Cognitive Pragmatics. Shanghai Foreign Language Education Press, 1999.

[2]. Liao Meizhen. The Principle of Goal Direction and Interaction of Speech Acts. Foreign Language Research, 2012, No. 5

[3]. Liao Meizhen. On the Linguistic Transition of Law, Social Science Front, 2006. No. 2

[4]. Li Zhenyu. New Speak on legal linguistics. China Procuration Press, 2006.6

[5]. Liu Yi. On the Ambiguity of Legal Language from the Perspective of Semantics. Journal of Xiangtan Normal University (Social Science Edition), 2008.5

[6]. Liu Xinglin. Interpreting Ambiguity in the Context. Journal of Xuzhou Normal University(Natural Science Edition), 2006.9.

[7]. Xing Xin. A Review of Domestic Research on Legal Linguistics. Applied Linguistics, 2004.11. 